\title{
Editorial
}

Victor Wünsch Filho ${ }^{1}$

\section{A RBSO em perspectiva}

RBSO in perspective

1 Professor Titular do Departamento de Epidemiologia da Faculdade de Saúde Pública da Universidade de São Paulo. Membro do Conselho Editorial da RBSO.
Quatro anos após a implantação efetiva da Fundação Centro Nacional de Segurança, Higiene e Medicina do Trabalho (Fundacentro), foi lançado o primeiro número da Revista Brasileira de Saúde Ocupacional (RBSO), referente aos meses de janeiro, fevereiro e março de 1973. Jorge Duprat Figueiredo, primeiro presidente da Fundacentro, dirigiu as palavras inaugurais aos leitores no editorial "A informação como instrumento do progresso". Alguns temas de Saúde e Segurança no Trabalho (SST), recorrentes ainda hoje, foram abordados naquele número.

O enfoque editorial do número pioneiro da RBSO traduzia o seu tempo. A mensagem, progresso como corolário do acesso à informação, estava em sintonia com o "milagre econômico brasileiro" que se encerraria naquele ano. Porém, ao longo das décadas desde 1973, ficou claro que o progresso desenfreado é deletério para a saúde dos indivíduos. Crescimento do produto interno bruto (PIB), somente, não significa desenvolvimento. Para isto é necessário buscar a equidade econômica e social e elevar a qualidade de vida da população em ambientes saudáveis e sustentáveis.

Nestes quase 40 anos de história, o país e o mundo passaram por transformações profundas. $\mathrm{O}$ acesso à informação, restrito no período de nascimento da RBSO, era um objetivo que permitiria avançar na área de SST. Hoje, a sociedade está imersa na era da informática e, submetida ao excesso de informações, precisa distinguir as relevantes. A conquista de melhor qualidade de vida dos trabalhadores, bem como da população em geral, mais do que informação exige conhecimento, ou seja, a informação qualificada obtida por meio de pesquisas transdisciplinares.

Desde o marco inicial, folhear os sucessivos números da RBSO é transitar, em diferentes épocas, pelos principais tópicos relacionados à SST, muitos dos quais tratados por ícones desta área no país. Mas examinar os volumes da RBSO também é perceber as crises em sua trajetória. Por alguns anos, com a descontinuidade da periodicidade, os artigos publicados perderam densidade. Consequentemente, sua importância ficou reduzida e sua penetração fraca na área de SST. A reversão desta tendência iniciou-se recentemente.

O editorial da publicação conjunta dos números 107/108, de 2003, informava que a RBSO passaria por mudanças no processo e na organização editorial. O número 114, do segundo semestre de 2006, com dossiê temático sobre o trabalho em teleatendimento, marca a inflexão em direção às mudanças anunciadas. As chamadas para números temáticos foram eficientes para atrair artigos de qualidade, alguns provenientes de dissertações de mestrado e teses de doutorado e, mesmo, de livre-docência. A análise das taxas de 
recusa de manuscritos submetidos à RBSO nos três últimos anos corrobora o fato. Em 2008, o volume 32 incluiu um número temático e outro por demanda espontânea, sendo recusados 80,6\% dos artigos sob avaliação. No volume 33, de 2009, formado por dois números com demanda livre, a recusa atingiu a desconcertante taxa de $88,9 \%$, embora o número de contribuições submetidas naquele ano tenha sido o mais elevado do período. Finalmente, em 2010, com dois números temáticos, a taxa de recusa recuou para $76 \%$.

Após o início do projeto de reestruturação, as pesquisas originais formam a maior proporção dos artigos publicados, característica marcante de um periódico científico. Os temas analisados são múltiplos na abrangência da área de SST, revelando as preocupações atuais em relação à saúde do trabalhador nas condições do mundo do trabalho no Brasil deste início do século XXI. Outro ponto a destacar, a RBSO recebe contribuições de diferentes regiões do país. A predominância é da produção científica oriunda da região Sudeste, mas há significativa participação do Nordeste e do Sul. Todavia, a representação das regiões Centro-Oeste e Norte é ainda limitada. A RBSO tem alcance e difusão nacional, porém vale registrar a presença de artigos provindos do exterior.

A produção científica contemporânea na área de SST floresce e emerge com vigor das páginas recentes da RBSO, entretanto, ainda há desafios a enfrentar. Embora períodos de transição sejam árduos para publicações científicas, obter a inserção da RBSO em redes mais amplas de indexação científica para aumentar sua visibilidade certamente é uma tarefa prioritária e um objetivo a ser atingido. Os pesquisadores da área de SST têm reagido positivamente às iniciativas de renovação da RBSO (MACHADO, J. M. H.; LACAZ, F. A. C. Respondendo a um chamamento! Revista Brasileira de Saúde Ocupacional, São Paulo, v. 35, n. 121, p. 6, jan./jun. 2010), mas é necessário que a elejam como lócus principal para a divulgação de seus melhores trabalhos. A RBSO é a única revista brasileira que comporta o espectro de temas específicos da Saúde do Trabalhador dentro da grande área da Saúde Coletiva. Congregar este conhecimento na RBSO estimulará um profícuo debate na área de SST sobre fatores determinantes das doenças ocupacionais, estratégias de prevenção e definição de políticas públicas para o controle.

O compromisso editorial assumido em 2007 (GARCIA, E. G.; JACKSON FILHO, J. M. Sobre o projeto de reestruturação da RBSO. Revista Brasileira de Saúde Ocupacional, São Paulo, v. 32, n. 116, p. 04-05, jul./dez. 2007) vem sendo seguido à risca. Os resultados são já evidentes e a consolidação da RBSO no tempo que há de vir é inexorável. A maturidade da comunidade de SST no Brasil para gerar conhecimento é a garantia deste futuro. 